\title{
Restoration by vacuum inflation of original alveolar dimensions in small human lung specimens
}

\author{
T.H. van Kuppevelt*, A.A. Robbesom*, E.M.M. Versteeg*, J.H. Veerkamp*, \\ C.L.A. van Herwaarden ${ }^{\#}$, P.N.R. Dekhuijzen ${ }^{\#}$
}

\begin{abstract}
Restoration by vacuum inflation of original alveolar dimensions in small human lung specimens. T.H. van Kuppevelt, A.A. Robbesom, E.M.M. Versteeg, J.H. Veerkamp, C.L.A. van Herwaarden, P.N.R. Dekhuijzen. C) ERS Journals Ltd 2000.

ABSTRACT: Resection of lung specimens results in deflated and distorted lung structures. If no major airway is present (as in the case of small lung specimens from biopsies), lung dimensions cannot be restored by inflation under $25 \mathrm{cmH}_{2} \mathrm{O}$. This impedes morphological analysis of the tissue. This report describes a simple and easy procedure to restore alveolar dimensions in deflated small lung specimens.

Small human lung samples were inflated using moderate vacuum conditions which are provided by a common water stream-driven vacuum device. Restoration of alveolar dimensions and morphology was evaluated for paraffin-embedded as well as frozen tissue, using morphometric and immunohistological analysis.

Vacuum inflation results in restoration of original lung dimensions as judged by light and scanning electron microscopy, and by analysis of the mean linear intercept, and the average length, width, perimeter and surface area. It also results in markedly improved cutting characteristics, allowing reliable sectioning of $2 \mu \mathrm{m}$ cryosections and achieving high resolution images in immunofluorescence.

Vacuum inflation is a simple and easy procedure to restore lung architecture of small human lung specimens/biopsies with a concomitant improvement of cutting characteristics. It allows for correct histological analysis of small specimens which cannot be inflated otherwise.
\end{abstract}

Eur Respir J 2000; 15: 771-777.

\author{
Depts of *Biochemistry and ${ }^{\#}$ Pulmonary \\ Diseases, University of Nijmegen, Nij- \\ megen, The Netherlands.
}

Correspondence: T.H. van Kuppevelt, Dept of Biochemistry, Faculty of Medical Sciences, 160 University of Nijmegen, P.O. Box 9101, 6500 HB Nijmegen, The Netherlands. Fax: 31243540525

Keywords: Alveolar dimensions emphysema

lung parenchyma

morphology

Received: June 231999

Accepted after revision December 61999

A.A. Robbesom and E.M.M. Versteeg were supported by Grants 93.55 and 95.44 from the Dutch Asthma Foundation.
Morphological assessment of lung specimens is an important tool for defining pathological conditions. Some disease entities, especially emphysema, are defined primarily on morphological criteria. Resection of lung (specimens) inevitably results in collapsed and deflated lung structures. This leads to apparent hypercellularity, a false impression of inflammation and fibrosis, and apparent alveolar wall thickening [1]. A correct morphological analysis of specimens is therefore not possible. In addition, use of cryosections, which for instance in the case of open lung biopsies allows for an immediate general impression of the disease process, is precluded due to collapse and additional compression during sectioning. Cryosections of such material are extremely difficult to interpret [1].

Lung dimensions can be restored by fixation of the lung under $25 \mathrm{cmH}_{2} \mathrm{O}[2,3]$. This, however, can only be accomplished if a large airway is present which can be easily cannulated (e.g. a bronchus). Obviously, this is not the case if only small specimens, like biopsies, are available. This presents a major draw-back not only in the field of diagnostics, but also for application of molecularbiological and biochemical techniques. These techniques allow analysis of small lung specimens, but meaningful interpretation of data can only be obtained if a correct histological analysis of the tissue is available.
This report here describes a simple, cheap and quick procedure to restore the original dimensions in small lung specimens, allowing correct histological evaluation. The procedure is based on inflation of the tissue using moderate vacuum conditions in the presence of fluid (fixative, buffer, etc.). The authors validated its usefulness by morphometric and immunohistological analysis, by evaluation of cutting characteristics, and by scanning electron microscopy.

\section{Materials and methods}

\section{Lung specimens}

Lung specimens were derived from nine patients who underwent lung surgery for bronchial carcinoma and from one individual at autopsy within $6 \mathrm{~h}$ after decease. This individual died of leukaemia, and had no record of lung diseases. Table 1 provides some characteristics of the patients. Subjects were studied according to the guidelines of the Committee of Medical Ethics of the University Hospital Nijmegen, the Netherlands and gave informed consent. Lung specimens were sampled at various places including subpleural and central regions. 
Table 1. - Characteristics of patients used in this study

\begin{tabular}{|c|c|c|c|c|c|c|c|c|}
\hline $\begin{array}{l}\text { Patient } \\
\text { No. }\end{array}$ & Age & Sex & $\begin{array}{l}\text { Smoking behaviour } \\
\text { pack-years }\end{array}$ & $\mathrm{S} / \mathrm{A}$ & Place of sampling & $\begin{array}{l}\text { TLC } \\
\% \text { pred }\end{array}$ & $\begin{array}{l}\text { FEV1 } \\
\% \text { pred }\end{array}$ & $\begin{array}{l}\text { KCO } \\
\% \text { pred }\end{array}$ \\
\hline 127 & 64 & M & s, 23 & $\mathrm{~S}$ & 111 & 79 & 82 & 81 \\
\hline 135 & 70 & $\mathrm{M}$ & s, 40 & $\mathrm{~S}$ & rul & 74 & 59 & 55 \\
\hline 192 & 66 & $\mathrm{~F}$ & $x, 60$ & $\mathrm{~S}$ & rul & 92 & 68 & 51 \\
\hline 193 & 68 & M & - & $\mathrm{S}$ & lul & 95 & 75 & - \\
\hline 194 & 65 & $\mathrm{M}$ & - & $\mathrm{S}$ & lul & 119 & 77 & - \\
\hline 229 & 64 & M & $\mathrm{x}, 25$ & $\mathrm{~S}$ & rul & 64 & 55 & - \\
\hline 230 & 60 & $\mathrm{~F}$ & s, 42 & $\mathrm{~S}$ & rul & 106 & 97 & 96 \\
\hline 232 & 56 & $\mathrm{M}$ & $\mathrm{s}, 10$ & $\mathrm{~S}$ & lul & 106 & 100 & 71 \\
\hline 233 & 55 & M & $x, 16$ & $\mathrm{~S}$ & rul & - & - & - \\
\hline 296 & 27 & M & - & A & $\mathrm{rul}, \mathrm{rml}, \mathrm{rll}, \mathrm{lul}, \mathrm{lll}$ & - & - & - \\
\hline
\end{tabular}

S: surgery; A: autopsy; TLC: total lung capacity; FEV1: forced expiratory volume in one second; KCO: transfer coefficient; M: male; F: female; s: current smoker; x: exsmoker (abstained smoking for >1 yr); - : not known; 1ll: left lower lobe; lul: left upper lobe; rll: right lower lobe; rml: right middle lobe; rul: right upper lobe.

\section{Inflation and processing of lung specimens}

Small lung specimens $\left(0.5-1 \mathrm{~cm}^{3}\right)$ were placed in glass vials containing either phosphate-buffered saline (PBS; $\mathrm{pH}$ 7.3; specimens for cryofixation), or PBS $+4 \%$ (weight (w)/ volume (v)) formaldehyde (samples for paraffin embedding). The vials were placed in a routine water streamdriven vacuum device (water aspirator), and degassed under vacuum $\left(1.33 \times 10^{4} \mathrm{~Pa}\right)$ for $10 \mathrm{~min}$. At that time the lung specimens, which initially floated on the fluid surface, were sunk to the bottom of the vials. Sinking is a good indication of successful degassing. In all cases, inflated and noninflated specimens were topographically matched. Specimens were processed for either paraffin embedding, or for cryofixation using isopentane cooled in liquid nitrogen followed by storage at $-70^{\circ} \mathrm{C}$. Paraffin sections $(4 \mu \mathrm{m})$ were contrasted using haematoxylin-eosin (HE) staining or trichrome staining according to GOLDNER [4]. Cryosections $(2 \mu \mathrm{m})$ were rehydrated for $10 \mathrm{~min}$ in PBS containing $1 \%$ bovine serum albumin (BSA), and immunostained for laminin and type IV collagen using rabbit anti-laminin immunoglobulin (Ig)G (Sigma Chemical Co., St. Louis, MO, USA), or goat anti-type IV collagen IgG (Southern Biotechnology Associates Inc., Birmingham, AL, USA), respectively. Bound antibodies were visualized using fluorescein isothiocyanate (FITC)-conjugated secondary antibodies (Sigma Chemical Co), or by avidin-biotinperoxidase based detection (Vectastain, Vector Laboratories Inc., Birlingam, CA, USA), using biotin-conjugated secondary antibodies (Jackson ImmunoResearch Lab., West Grove, PA, USA). Peroxidase activity was visualized using 3-3'-diaminobenzidine as the substrate. All antibodies were applied for $1.5 \mathrm{~h}$ in PBS containing 1\% BSA. After each antibody incubation, sections were washed in PBS (three times for $5 \mathrm{~min}$ ). Sections were embedded in aquamount or Entellan (Merck, Darmstadt, Germany) and examined on a Zeiss axioskop photomicroscope (Carl Zeiss, Oberkochen, Germany). For scanning electron microscopy, aldehyde-fixed tissue was dehydrated, critical point dried, sputtered with gold, and examined in a JEOL JSM-6310 (JEOL Ltd, Welwyn Garden City, Herts, UK) scanning electron microscope.

\section{Determination of parenchymal dimensions}

To quantitate the effect of inflation the mean linear intercept $(\mathrm{Lm})$, a measure for the average diameter of air spaces $[5,6]$ was measured. In addition, the average length, width, perimeter and surface area of individual alveoli were analysed. Only tissue with open structures were taken into account. Consequently, $\sim 80 \%$ of the tissue of noninflated specimens was not included. Using a CCD camera, and PC Image $\mathbb{R}$ (Foster Findlay, Newcastle-upon-Tyne, UK) and Photo Paint $\AA$ (Corel Corporation, Ottawa, Ontario, Canada) software, images were digitized and printed onto paper. The Lm was assessed using two transparent sheets with horizontal and vertical lines drawn on it. Intercepts of airspace walls with these lines were counted manually and the total of these intercepts was divided by the total length of the lines. Intercepts from blood vessels and bronchioles were counted for one half since airspaces are also located next to these structures.

Values were corrected for tissue shrinkage by measuring the dimensions of lung specimens before and after histological processing. The correction factor was 0.82 , in
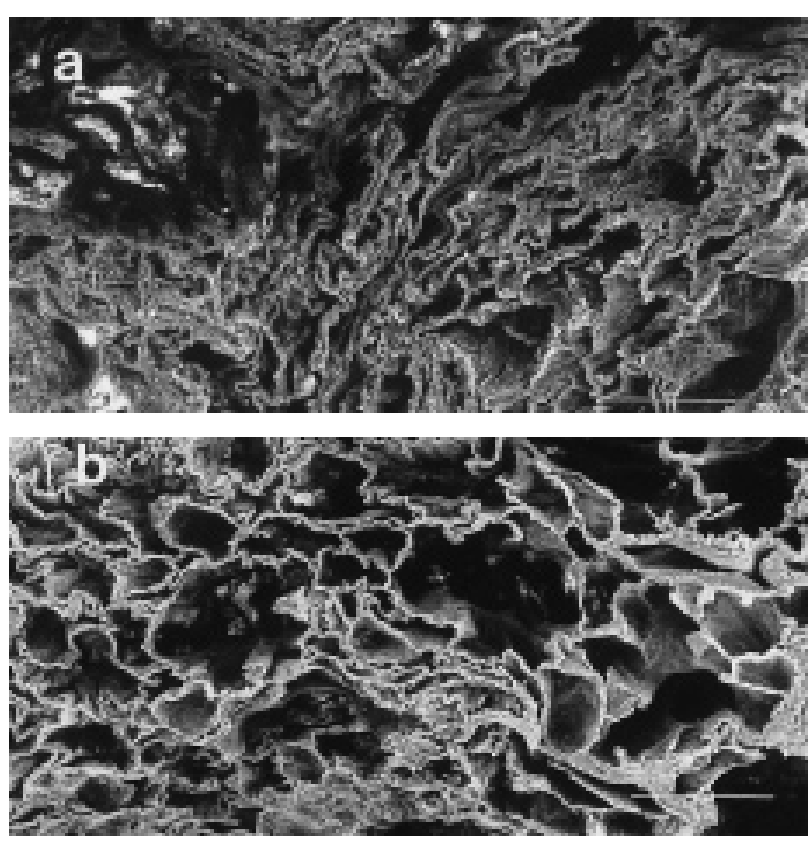

Fig. 1. - Scanning electron micrograph of a small parenchymal lung specimen which has not (a), or has (b) been vacuum-inflated. Note the open alveoli in a). Patient No. 232. Internal scale bars $=250 \mu \mathrm{m}$. 

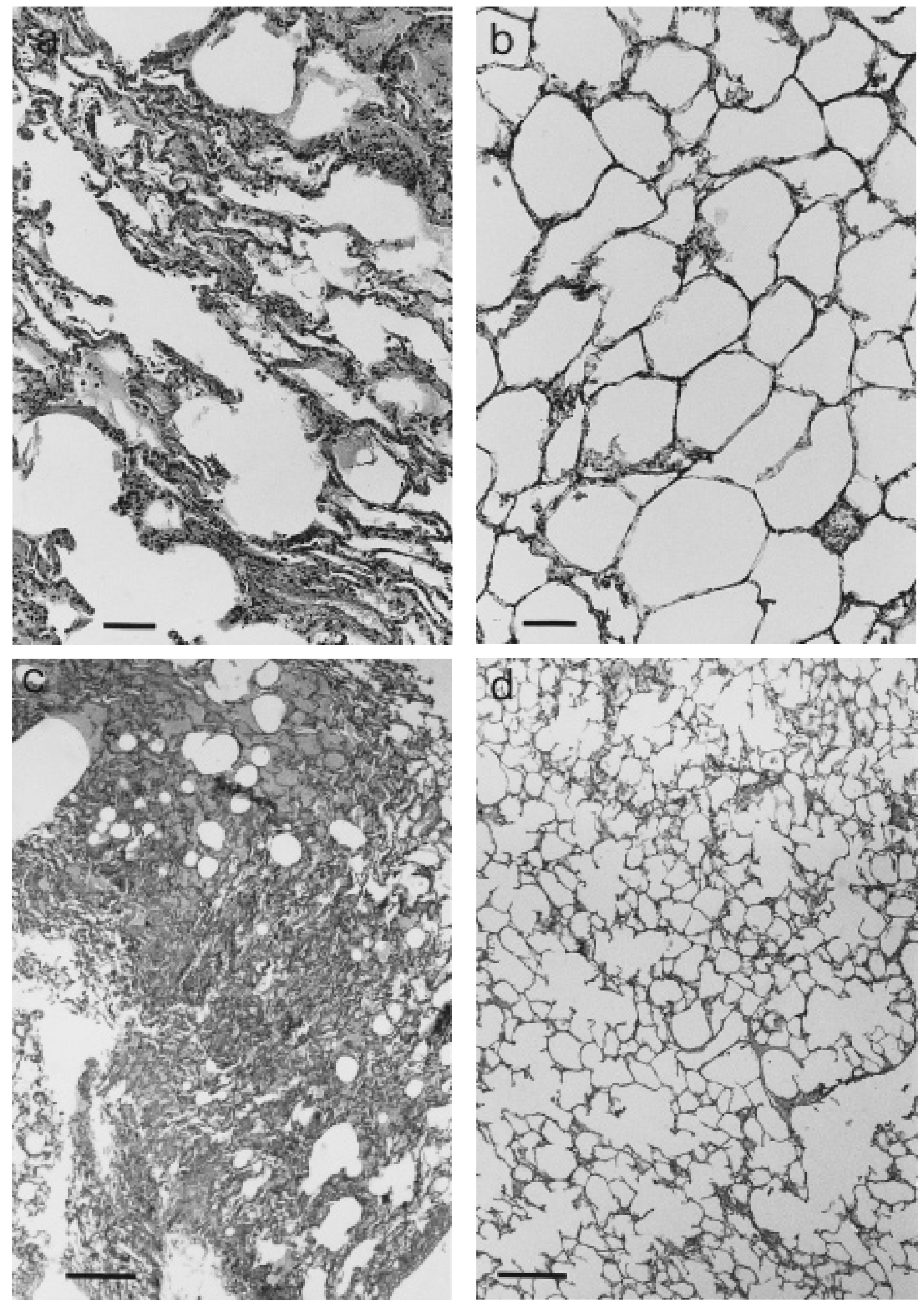

Fig. 2. - Light microscopical images of paraffin sections from lung specimens which have not (a, c), or have (b, d) been vacuum-inflated. Inflation was performed in phosphate-buffered saline containing 4\% formaldehyde. Haematoxylin-eosin staining. Patient No. 296. Note the apparent hypercellularity and wall thickening in a) and major collapse and trapped air bubbles in c). Internal scale bars a) and b) $=100 \mu \mathrm{m}$; c) and d) $=500 \mu \mathrm{m}$. 
accordance with data from WeIBEL [7]. The obtained value represents the mean diameter of a single air space. Per specimen, a minimum of 2,000 horizontal and 2,000 vertical counts were analysed. Next to the Lm, the average length, width, perimeter, and surface area of individual alveoli were measured. Using PC Image $\mathbb{R}$ ) (Foster Findlay) software, alveolar images were digitized and the various parameters calculated.

\section{Statistical analysis}

Values are given as mean \pm SD or SEM, as indicated. Intergroup comparison was calculated using the Mann-Whitney U-test. P-values $<0.05$ are considered significant.

\section{Results and discussion}

\section{Morphology}

Comparison of noninflated and inflated small lung tissue reveals strikingly different images (fig. 1). Vacuuminflated tissue demonstrates a much more open structure as compared to noninflated tissue. The mechanism of vacuum inflation may be explained as follows. By application of vacuum conditions the lung specimens, which were originally at atmospheric pressure, will expand and trapped air will be released. Concomitantly, fluid (fixative, PBS, etc.) will fill up and stabilize the expanded tissue. In this way, the increase in volume is maintained at release of the vacuum conditions. Vacuum inflation may
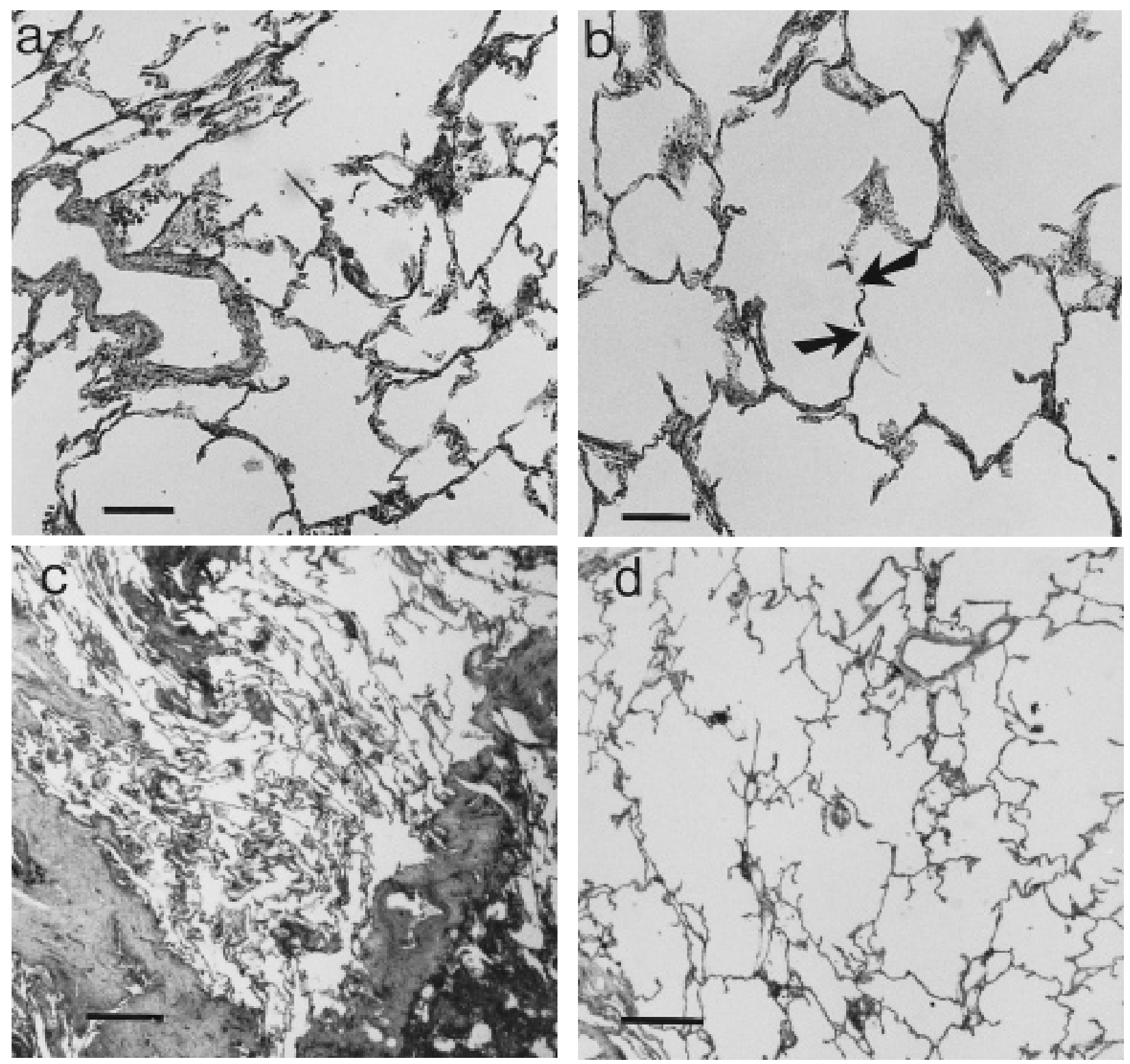

Fig. 3. - Light microscopical images of paraffin sections from lung specimens which have not (a, c) or have (b, d) been vacuum-inflated. Inflation was performed in phosphate-buffered saline containing $4 \%$ formaldehyde. Haematoxylin-eosin staining. Patient No 230 (a, b) and 233 (c, d). Note alveolar breaks in b) (arrows). Internal scale bars a) and b) $=100 \mu \mathrm{m}$; c) and d) $=500 \mu \mathrm{m}$. 
Table 2. - Mean linear intercept of small specimens of parenchymal lung tissue without and with vacuum inflation

\begin{tabular}{lccc}
\hline & \multicolumn{2}{c}{ Mean linear intercept* $\mu \mathrm{m}$} & \\
\cline { 2 - 3 } $\begin{array}{l}\text { Patient } \\
\text { No. }\end{array}$ & $\begin{array}{c}\text { Noninflated } \\
\text { tissue }\end{array}$ & $\begin{array}{c}\text { Inflated } \\
\text { tissue }\end{array}$ & $\begin{array}{c}\text { Relative } \\
\text { increase\% }\end{array}$ \\
\hline 229 & $132 \pm 19$ & $201 \pm 32$ & 52 \\
230 & $249 \pm 25$ & $300 \pm 61$ & 20 \\
232 & $228 \pm 21$ & $300 \pm 45$ & 32 \\
233 & $286 \pm 22$ & $338 \pm 47$ & 18 \\
296 & $187 \pm 19$ & $223 \pm 20$ & 20 \\
\hline
\end{tabular}

Values are mean $\pm \mathrm{SD}$. *: collapsed tissue was not measured.

be especially effective for human lung parenchyma since human alveoli are more prone to collapse than alveoli of rodents, due to their large diameter.

\section{Paraffin embedded tissue}

Lung specimens from deflated lungs reveal collapsed parenchymal tissue and distorted lung architecture (figs. 2a, c and 3a, c). Apparent hypercellularity and thickening of alveolar walls become evident in such tissue (e.g. fig. 2a). These artefactual phenomena are not present in vacuum-inflated tissue (figs. 2b, d, and 3b, d). Vacuum inflated lung specimens display open air spaces and normal parenchymal architecture. In addition, alveolar walls are stretched rather than curled, and details like alveolar breaks become readily apparent (fig. 3b). This is of importance, for example, when morphometric parameters as the destructive index are analysed. The destructive index is a parameter of parenchymal destruction, alveolar breaks being a major determinant in its assessment [2]. Alveolar breaks may go undetected if alveolar septa are collapsed. The beneficial effect of vacuum inflation was observed for all specimens from all 10 patients examined, regardless the place of sampling.

To substantiate the qualitative observations, the $\mathrm{Lm}$ and the average alveolar area, perimeter, length and width were determined for 2-5 patients (tables 2 and 3, fig. 4). It should be noted that completely collapsed tissue, frequently observed in deflated tissue, was excluded from morphometric analysis. On average, the $\mathrm{Lm}$ increases by $\sim 30 \%$ after vacuum inflation. This is in line with the $\sim 30 \%$ increase of width, length, and height as observed macroscopically. The dimensions of individual alveoli are also increased considerably (table 3 ). Alveoli in inflated tissue have larger surface areas than those of noninflated tissue (fig. 4). All values obtained after inflation of the
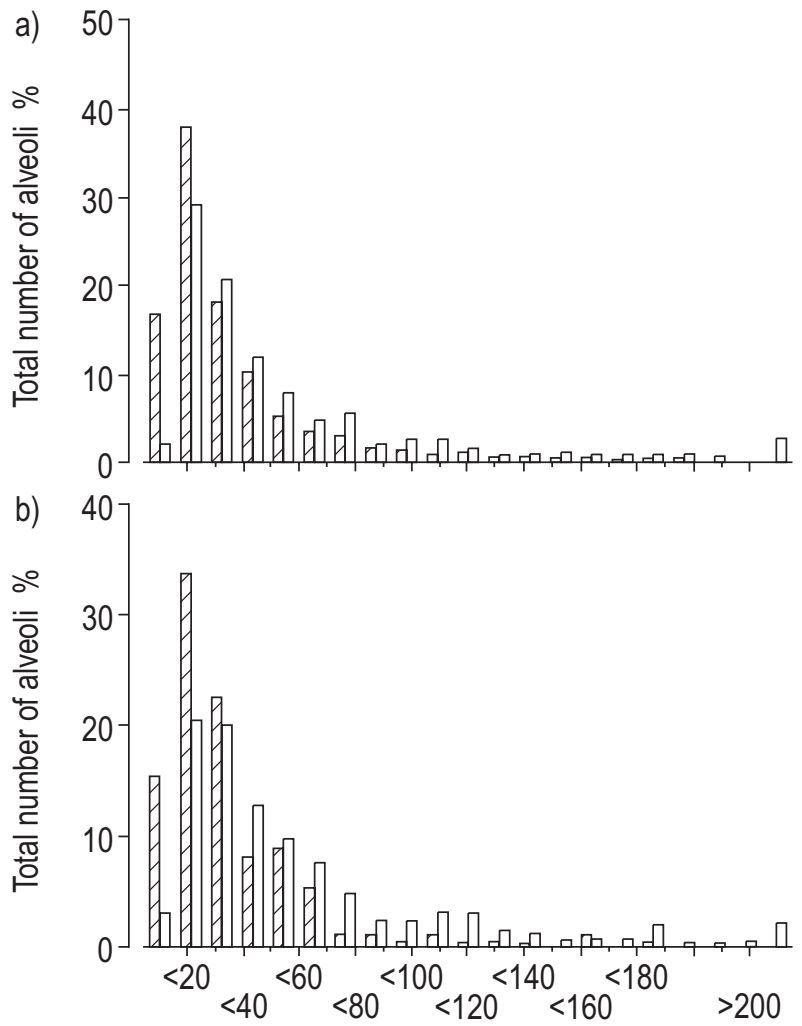

Alveolar surface area in $1,000 \mu^{2}$

Fig. 4. - Relative distribution of alveolar surface area in lung specimens which have, or have not been vacuum-inflated. Inflation was performed in phosphate-buffered saline containing $4 \%$ formaldehyde. a) A total of 478 and 939 individual alveoli were analysed in inflated and noninflated tissue, respectively, of patient No. 230. b) A total of 589 and 262 individual alveoli were analysed in inflated and noninflated tissue, respectively, of patient No. 232. $\mathbb{Z}$ : noninflated; $\square$ : inflated.

lung samples are comparable to those obtained after inflation of whole lung lobes at $25 \mathrm{cmH}_{2} \mathrm{O}$, indicating restoration of original dimensions [1-3, 5-9].

\section{Frozen tissue}

Cryosections of deflated parenchymal tissue show completely collapsed tissue (fig. 5a, c). The parenchymal architecture is destroyed and morphological analysis is not possible. After vacuum inflation, the open structure is restored (fig. 5b, d, and fig. 6), including open alveolar capillaries (fig. $6 \mathrm{~b}, \mathrm{c}$ ). In many cases, the morphology of inflated cryofixed tissue matches that of aldehyde-fixed

Table 3. - Dimensions of alveoli in lung specimens with and without vacuum inflation

\begin{tabular}{|c|c|c|c|c|}
\hline \multirow{2}{*}{ Parameter* } & \multicolumn{2}{|c|}{ Patient No. 230} & \multicolumn{2}{|c|}{ Patient No. 232} \\
\hline & Noninflated & Inflated & Noninflated & Inflated \\
\hline $\mathrm{n}$ & 939 & 478 & 262 & 589 \\
\hline Average length $\mu \mathrm{m}$ & $190 \pm 3$ & $242 \pm 5$ & $185 \pm 4$ & $267 \pm 5$ \\
\hline Average width $\mu \mathrm{m}$ & $116 \pm 2$ & $152 \pm 3$ & $114 \pm 3$ & $165 \pm 3$ \\
\hline Average perimeter $\mu \mathrm{m}$ & $540 \pm 9$ & $750 \pm 19$ & $507 \pm 14$ & $806 \pm 18$ \\
\hline Average surface area $\mu \mathrm{m}$ & $27930 \pm 850$ & $47166 \pm 2230$ & $27634 \pm 1532$ & $52200 \pm 2073$ \\
\hline
\end{tabular}

Values are mean \pm SEM. For all parameters, values for noninflated and inflated tissue differ significantly $(\mathrm{p}<0.0001)$. ${ }^{*}$ collapsed tissue was not measured; n: number of individual alveoli. 

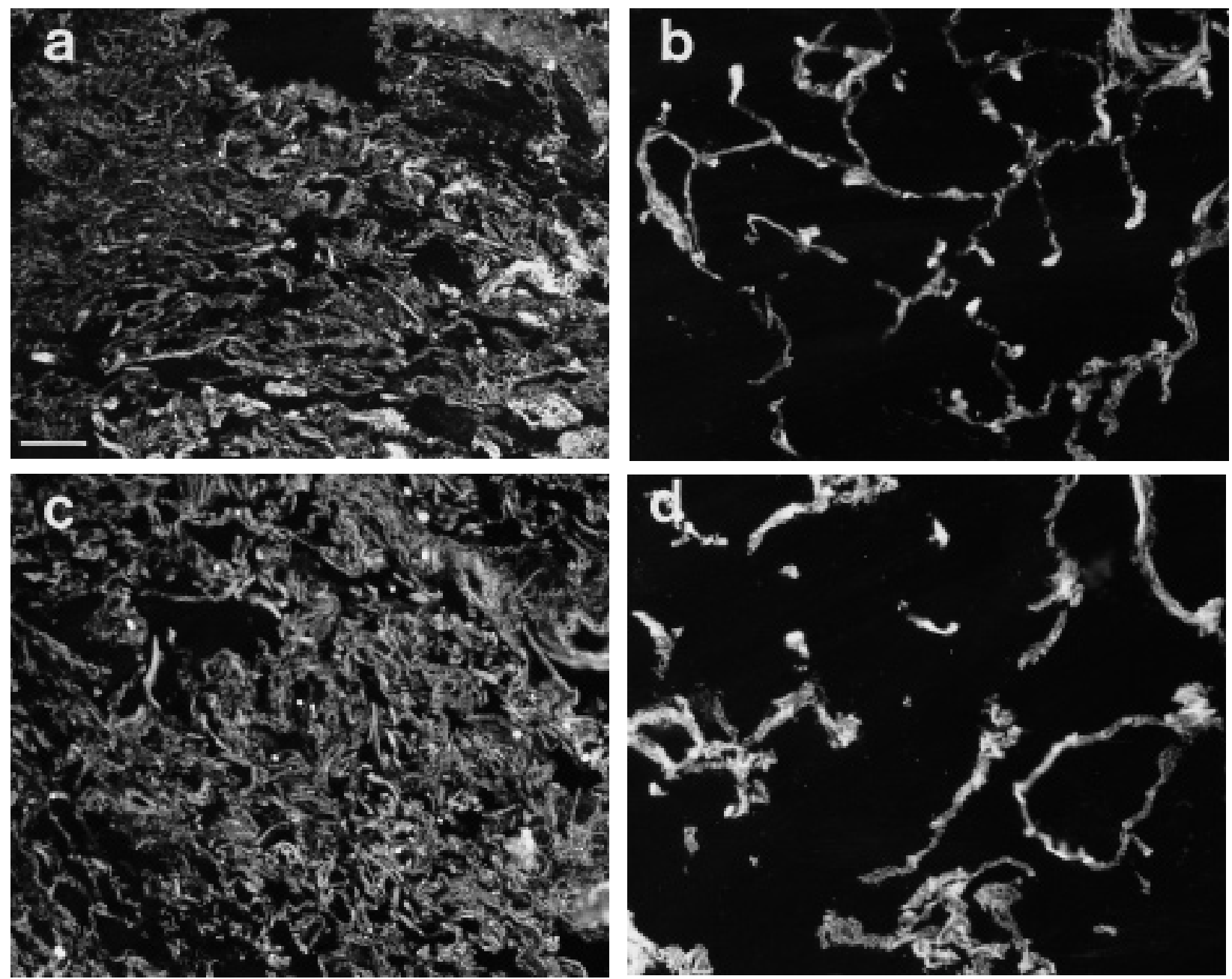

Fig. 5. - Cryosections from lung specimens which have not (a, c), or have (b, d) been vacuum-inflated. Patient Nos 193 (a, b) and 192 (c, d). Inflation was performed in phosphate-buffered saline. Parenchymal tissue was visualized by immunostaining for laminin, a general basement membrane component. Note the complete collapse of the noninflated specimens, in contrast to the open tissue architecture of the inflated specimens. Internal scale bar $=100 \mu \mathrm{m}$.

and paraffin-embedded tissue (e.g. compare fig. 6a with fig. 2b). This allows correct morphological interpretation of cryosections and is of importance not only from a scientific point of view, but also if immediate histological information is needed, e.g. during surgery. In addition, cryosections from vacuum inflated tissue allow high resolution immunohistochemistry. Using an antibody to a general basement membrane component (e.g. type IV collagen), alveolar and capillary basement membranes in the alveolar wall can be discerned (fig. 6c).

\section{Cutting characteristics}

Apart from the contribution of the expansion of the tissue per se by vacuum inflation, the improved cutting characteristics of the lung specimens also play a role in the restoration of the original parenchymal architecture. Lung tissue is prone to compression during sectioning because of its specific nature, i.e. the presence of many tissue/air interfaces. Noninflated lung blocks are difficult to section, which especially holds true for frozen tissue. Cryosections frequently disintegrate, rows ("ribbons") of sections are difficult to obtain and thin sectioning $(1-2 \mu \mathrm{m})$ is cumbersome. Noninflated frozen sections are therefore very difficult to interpret. Vacuum inflated tissue shows markedly improved cutting characteristics, allowing reliable and routine sectioning of ribbons of $1-2 \mu \mathrm{m}$ cryosections. Compression during sectioning is strongly reduced. The cutting characteristics of paraffin blocks are improved as well, especially the sectioning of large surfaces. The friability of the sections is reduced. Air holes in paraffin sections, caused by trapped air during the embedding procedure, are largely prevented (fig. 2c, d). The improved sectioning characteristics are probably due to the lack of trapped air, and concomitant better penetration of fluids such as fixative, dehydrating agents and embedding media (e.g. paraffin).

In conclusion, vacuum inflation of small lung specimens results in restoration of the original alveolar dimensions. Cutting characteristics are markedly improved. Vacuuminflated tissue allows better interpretation of affected and nonaffected lung tissues, thereby improving proper 


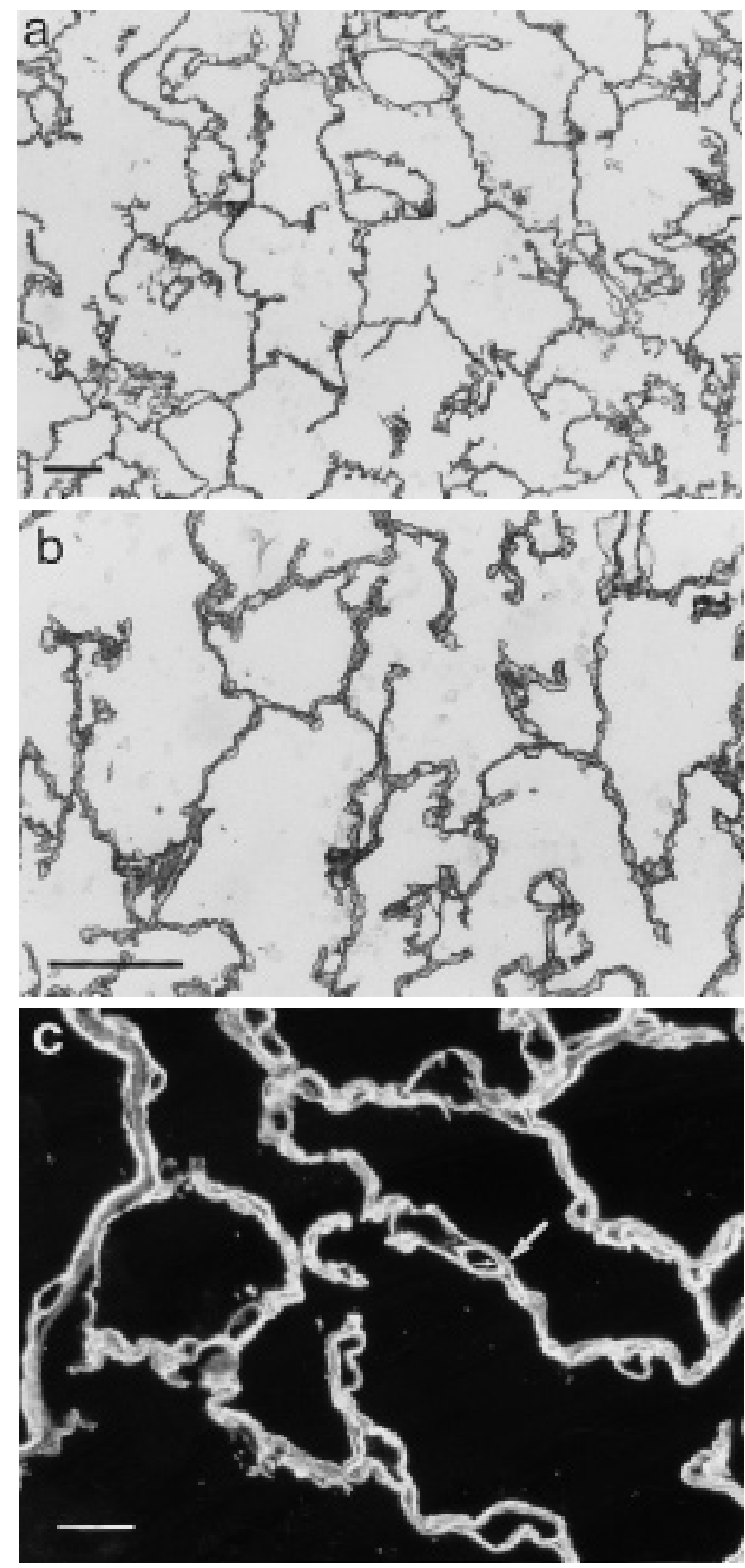

Fig. 6. - High-resolution immunostaining of vacuum-inflated cryo-fixed parenchymal lung tissue. Inflation was performed in phosphate-buffered saline. a) and b) Immunoperoxidase staining for type IV collagen, a general basement membrane component, using avidine-biotin technology. a) low magnification; b) high magnification. Note open alveolar capillaries. Patient No. 127. c) Immunofluorescence staining for type IV collagen. Note open alveolar capillaries. Alveolar- (large arrow), and capillary- (small arrow) basement membranes can be discerned. Patient No 135. Internal scale bars a) and b) $=100 \mu \mathrm{m}$; $)=20 \mu \mathrm{m}$. evaluation of morphological alterations and thus diagnosis. Application of this procedure may increase the possibilities of using small biopsies for diagnostic purposes. Although in this study only lung resection specimens were used for analysis, it is likely that the present inflation technique is also applicable in open lung biopsies, as for example obtained by video-assisted thoracoscopic surgery, and in peripheral lung tissue specimens obtained by bronchoscopy. Subsequent studies, however, are needed to confirm this assumption. In addition, the inflation technique may be of importance in basic research. Contemporary molecularbiological and biochemical techniques now allow the use of only minute amounts of tissues, but meaningful interpretation of molecular data is only possible if proper morphology is at hand. The procedure of vacuum inflation can be very instrumental in this respect.

Acknowledgements. The authors wish to express their gratitude to the staff and members of Dekkerswald Medical Center Groesbeek, the Netherlands, for providing the lung specimens and for stimulating discussions.

\section{References}

1. Miller RR, Evans KG. Lung biopsy. In: Thurlbeck WM, Churg AM, eds. Pathology of the Lung. New York, USA, Thieme Medical Publishers, 1995; pp. 107-115.

2. Saetta M, Shiner RJ, Angus GE, et al. Destructive index: a measurement of lung parenchymal destruction in smokers. Am Rev Respir Dis 1985; 131: 764-769.

3. Saito N, Cagle P, Berend N, Thurlbeck WM. The "destructive index" in nonemphysematous and emphysematous lungs: morphologic observations and correlations with function. Am Rev Respir Dis 1989; 139: 308-312.

4. Goldner J. A modification of the Masson trichome technique for routine laboratory purposes. Am J Pathol 1938; 14: 237.

5. Dunnill MS. Quantitative methods in the study of pulmonary pathology. Thorax 1962; 17: 320-328.

6. Thurlbeck WM. Measurement of pulmonary emphysema. Am Rev Respir Dis 1967; 95: 752-764.

7. Weibel ER. Morphology of the lung. Berlin, Germany, Springer Verlag, 1963.

8. Verbeken EK, Cauberghs M, Mertens I, Clement J, Lauweryns JM, Van de Woestijne KP. The senile lung: comparison with normal and emphysematous lungs. I. Structural aspects. Chest 1992; 101: 793-799.

9. Verbeken EK, Cauberghs M, Mertens I, Clement J, Lauweryns JM, Van de Woestijne KP. Anatomy of membranous bronchioles in normal, senile and emphysematous human lungs. J Appl Physiol 1994; 77: 1875-1884. 